\title{
Workforce Resources for Health in Developing Countries
}

\author{
Shrikant I. Bangdiwala MS, PhD, ${ }^{1}$ \\ Sharon Fonn MBBCh, $\mathrm{PhD},{ }^{2}$ \\ Osegbeaghe Okoye MBBS, MPH, ${ }^{3}$ \\ Stephen Tollman MMed, MA, MPH, $\mathrm{PhD}^{4}$
}

\begin{abstract}
With increased globalization and interdependence among countries, sustained health worker migration and the complex threats of rapidly spreading infectious diseases, as well as changing lifestyles, a strong health workforce is essential. Building the human resources for health should not only include healthcare professionals like physicians and nurses, but must take into consideration community health workers, mid-level workers and strengthened primary healthcare systems to increase coverage and address the basic health needs of societies. This is especially true in low and middle-income countries where healthcare access is a critical challenge.

There is a global crisis in the health workforce, expressed in acute shortages and maldistribution of health workers, geographically and professionally. This massive global shortage, though imprecise quantitatively, is estimated at more than 4 million workers. To respond to this crisis, policies and actions are needed to address the dynamics of the health labour market and the production and management of the health workforce, and to strengthen the performance of existing health systems. Schools of public health need to develop the range of capacity and leadership in addition to the traditional training of healthcare managers and researchers. Countries should first identify their health problems in order to properly address their health worker needs, retention, recruitment and training, if they are to come close to reaching the Millennium Development Goals (MDGs) for health.
\end{abstract}

\footnotetext{
${ }^{1}$ Department of Biostatistics, Gillings School of Global Public Health, The University of North Carolina at Chapel Hill, USA; University of South Africa, Johannesburg.

${ }^{2}$ School of Public Health, University of the Witwatersrand, Johannesburg, South Africa.

${ }^{3}$ 2B Degema Close, Rumuibekwe Housing Estate, Port Harcourt, Nigeria.

${ }^{4}$ MRC/Wits Rural Public Health and Health Transitions Research Unit School of Public Health, University of the Witwatersrand, Johannesburg, South Africa; Epidemiology and Global Health, Umeå University, Sweden.
}

Correspondence: Shrikant Bangdiwala at email kant@unc.edu 
Key Words: health workforce, globalization, Millennium Development Goals, subSaharan Africa health, Nigeria health, primary healthcare, mid-level health workers, community health workers

\section{INTRODUCTION}

The mobilization and strengthening of human resources for health has been neglected in many countries, but remains a key ingredient in combating health crises in some of the world's poorest countries, and for building sustainable health systems. The challenges faced in optimizing human resources for health are numerous, starting with the need to identify basic healthcare issues globally and nationally, and finding ways to provide integrated care. Geographical variation needs to be addressed, with large disparities in the workforce between and also within countries. ${ }^{1}$

Countries with poor economies and weak healthcare infrastructure are likely to also be the ones with the most inadequate human resources for health. Such countries tend to have the greatest difficulty in developing the resources to build the capacity of and expand the absolute numbers of health workers. The number of professionals trained in medical and nursing schools and the number of health managers and researchers trained in the schools of public health may be inadequate. Just as important, there may be inadequate numbers of mid-level workers, lay community health workers, midwives and other healthcare providers. The mix of professional and nonprofessional healthcare workers is another consideration. Beyond the availability of adequately trained personnel, two points stand out: a critical need for both service and political leadership of developing health systems; and an adaptation of delivery systems to the specific needs of country and local settings..$^{2-4}$

A major challenge in the new millennium is the retention of health workers, not only in poorer countries, but also within any country in remote and rural areas. Thus, an understanding of factors such as inadequate infrastructure, inadequate salaries, or intangibles, that influence the decisions of health workers to leave or to stay, and the strategies effective for retention, is imperative..$^{5-7}$

The phenomenon of inadequate numbers of doctors internationally, exacerbated by the maldistribution of doctors who are over-represented in the private sector, in cities and in wealthier countries, has left those in most need (poor, rural, and marginalized individuals and groups) underserved. The World Health Organization indicates that about 4 million health workers are needed globally. The number of healthcare workers per 
thousand population in 2006 was estimated to be 2.9/1000 in Africa; 5.8/1000 in Southeast Asia; 14.9/1000 in the Americas (North and South) and 40.3/1000 in Europe. ${ }^{8}$ However, the quality of data - in particular, the poor state of health information system data on human resources in lowincome countries - has meant that estimates vary. ${ }^{9}$ Data are hard to compare, as estimates vary depending on how the term "health worker" is defined, and summary figures, in particular composite regional data, obscure the within and between country differences. The pattern, however, is clear: low resource settings have a very high population-to-provider ratio. Undersupply of health professionals is not uniform; in countries that make up the Central Asian Commonwealth of Independent States, it is the quality rather than number of providers - as well as the hospital-centric focus of the health system - that is the challenge.

Africa comprises some 11 percent of the world population, yet accounts for 25 percent of the global burden of disease and hosts just 4 percent of the global health workforce to address this. ${ }^{8,10}$ There are urgent health needs in the region: Of the 20 countries with the highest maternal mortality rates in the world, 19 are in Africa; eleven of the 15 countries with the highest incidence of tuberculosis are in Africa; malaria is endemic in 42 of the 46 member states of the WHO Africa Region, and accounts for over 90 percent of estimated clinical cases worldwide. Two-thirds of the world's people living with HIV, and 72 percent of AIDS deaths occur in Africa. ${ }^{11,12}$ The continent faces an extreme human health resource shortage estimated at 720,000 physicians and 670,000 nurses. ${ }^{13}$

In this article, we first sketch the nature of change in the burden of illness experienced by many middle- and low-income countries, followed by comments on key issues affecting the performance of health systems. In response to the challenge of inadequate health workforce numbers and distribution, there is a trend to consider alternative cadres who can deal effectively with common health problems and improve access to services in both rich and poor countries. In particular, we focus on two alternatives to professional medical and nursing practitioners: community health and midlevel workers as essential primary healthcare (PHC) providers. A case study of Nigeria illustrates the enormous challenges to the health workforce that faces developing countries more generally. 


\section{FOCUS ON PRIMARY HEALTHCARE (PHC)}

\section{Changing burden of illness and the dynamics of health transition}

A growing body of research attests to the changing burden of illness in subSaharan Africa. While the unfinished agenda of infection, malnutrition and maternal complications persists in a diversity of settings, longstanding malaria, and the recent and extensive upsurge in HIV/AIDS and tuberculosis ${ }^{14}$ is paralleled by the emergence of chronic vascular disease, diabetes, cancers and lower respiratory conditions, which now constitute the commonest causes of death. Equally, the range of accidents and injuries is prominent, as is growing recognition of mental illness and its consequences. ${ }^{15,16}$

Taken together, this profile characterizes a complex, changing pattern of illness that imposes a significant burden on households and communities, and which - through a mix of chronic infectious and non-communicable diseases - places quite unfamiliar challenges on health and social systems.

\section{Health systems and access to care}

Health systems and the delivery of PHC appear to have weakened over the past 2 decades. ${ }^{17}$ While no single issue is solely responsible, a number of longstanding insults can be singled out. The macroeconomic context of increased debt since the late 1970s consequent on the oil crisis, a focus on debt repayment, decreasing investment in social institutions, and an erroneous belief in the limited role of the state and the importance of the private sector, form the backdrop against which the state of current health systems must be seen.

Poor human resource management is a widespread and critical factor, with the effects of accumulated managerial and clinical care deficiencies clearly apparent. This is underpinned by excessive levels of health worker migration - from the public to the private sector, rural to urban settings, or to more welcoming and lucrative destinations abroad. ${ }^{18}$

Today, there is unusual flux in health systems thinking, a product of weak systems performance, coupled with disappointing progress in meeting disease reduction targets, and reflected - certainly in sub-Saharan Africa with the recognition that much of the continent will fall far short of its Millennium Development Goals. Similarly, there is a growing consensus on the vital importance of a functioning health systems platform as the foundation for the delivery of programs and interventions, irrespective of their specific foci. ${ }^{19,20}$ 


\section{Implications for primary healthcare}

These challenges - a still-evolving and complex burden of illness and concerns with health systems development and performance - refocus attention on PHC. Restoring focus on health systems strengthening and effective PHC is central to the World Health Organization's current phase of work. This is emphasized in statements by the Director-General, Margaret Chan ${ }^{21}$; in the Organization's 2008 World Health Report - Primary Health Care: Now more than ever $^{22}$; and the findings of two recent high-level commissions: the WHO Commission on Macroeconomics and Health and the WHO Commission on the Social Determinants of Health..$^{23,24}$ Similarly, recent findings of the Disease Control Priorities Project underline the costeffectiveness of quality primary healthcare - highly relevant given the pressures on national spending in the wake of the current global recession..$^{25,26}$

With greater recognition of the limitations and unintended consequences of vertical, unifocal disease-oriented programs, particularly in eroding or failing to develop the primary care infrastructure, the call for integrated health programming - in childhood and adult illness, chronic disease, maternal and reproductive health, HIV and tuberculosis care - is becoming clearer. Such integrated care systems, still warranting concerted research and development, will depend by definition on adequately functioning primary care delivery platforms. ${ }^{14,27}$ In part, this may be achievable by recognition of this need by international donor agencies, and by the concerted action of national governments.

The part of the health system that needs 're-engineering' is the way in which the system interacts with households and communities so that health services can impact positively on population health. Notably, with the rise of chronic conditions, reorienting care systems to achieve continuity of care is vital. This will require a changed relationship between health workers and patients, with mutual respect and service-client partnership a key to successful clinical outcomes. These greater demands on health workers only exacerbate the critical shortage of human resources for health. In response, not only must existing systems change, but the role of additional cadres is high on the international agenda. ${ }^{28,29}$

\section{COMMUNITY-BASED HEALTH WORKERS: AN ALTERNATIVE}

Community-based health workers (CHWs) are referred to by a variety of names, such as health auxiliaries, health volunteers, health promoters, family welfare educators, village health workers, and community lay health 
aides. Regardless of name, they are involved in providing preventive medical services, monitoring the community's health, identifying patients at particular risk, and perhaps even providing basic curative services. Their use is a model which is widely implemented by many countries as a vital part of management of specific diseases, such as tuberculosis, malaria and others, with important potential, even in industrialized countries, for specific tasks such as in tuberculosis management using DOTS (Directly Observed Therapy, Short-course), and in management of chronic diseases.

Clearly, CHWs do not function independently or in a vacuum. While voluntary work may in some situations be workable, it generally runs the risk of being poorly integrated with the formal health system, poorly supported, and taken for granted by service managers - with obvious consequences for effectiveness and sustainability. Further, it often undervalues the efforts, time and cost that voluntary workers provide (often themselves from poor communities), and makes regulating their work and ensuring quality difficult.

An effective PHC team, responsible for a defined community and (generally) working from a health centre base, must have the capacity to: link clinical care with prevention-oriented community mobilisation; manage and support patients close to their homes; and bridge actions needed across sectors (such as agriculture, transport, local government, education, welfare, natural resources and labour). To these should be added the familiar requirements of cultural appropriateness in respect of local beliefs, customs and language.

No matter how hardworking, these conditions will not be fulfilled by traditional doctor-nurse teams, subject to conventional hierarchies, nor by the growing range of mid-level workers. Rather, it is sizeable numbers of well-trained and supported CHWs, integrated into properly functioning PHC teams that are an additional, essential element to meet the healthcare needs of communities. The WHO advocates such an approach in resourcelimited settings for providing antiretroviral treatment against HIV. ${ }^{29}$

\section{Recent CHW experience}

Recent experience tends to bear out these assertions. The decline in enthusiasm for CHW programs in the 1980s was due to problems, such as "unrealistic expectations, poor initial planning, problems of sustainability, and the difficulties of maintaining quality" experienced by large-scale and national programs. ${ }^{30,31}$ Yet CHW programmes have re-emerged globally, mainly to address shortages in qualified health workers in many countries. In sub-Saharan countries, this is mainly due to the increased needs (diagnosis, treatment and care) generated by HIV/AIDS..$^{32-34}$ 
Several studies have shown that CHWs can provide excellent care to HIV/AIDS patients. A study conducted in Kampala, Uganda demonstrated that a comprehensive community-based highly active antiretroviral therapy (HAART) program using peer health workers and nurses provided very good AIDS care, including good virologic outcomes. ${ }^{35}$ Data from a study from Free State Province, South Africa, showed that the availability of treatment buddies, CHWs and support groups was the most important predictor of treatment success (assessed by CD4 cell count and viral load) throughout the first two years of treatment. ${ }^{36}$

CHWs are also gaining support in managing other communicable diseases such as malaria and tuberculosis. For example, rapid diagnostic tests for malaria were accepted and easily used by CHWs in Lusaka Province, Zambia in 2006, resulting in timely detection and the avoidance of overtreatment. ${ }^{37}$ Further, there is good evidence that CHWs can undertake various tasks contributing to child survival. The case management of childhood illness and delivery of preventive interventions such as immunisation are good examples. . $^{30,38,39}$

A study in the Western Cape Province, South Africa, concluded that lay health workers achieved better outcomes for patients with considerable cost saving when compared with clinic-based care. Trained CHWs were able to improve the treatment success rate among tuberculosis patients in a well-established health service despite a reduction in the range of services available. $^{40}$

A recent updated systematic review of 82 randomised controlled trials on the effectiveness of lay health workers in a variety of settings showed that they provide promising benefits in promoting immunization uptake and breastfeeding practices, improving TB treatment outcomes, and in reducing child morbidity and mortality when compared to usual care..$^{38}$

\section{MID-LEVEL WORKERS}

Mid-level workers (MLWs) are certificated individuals who are not doctors but have been trained to "diagnose and treat common health problems, to manage emergencies, to refer appropriately and to transfer the seriously ill or injured for further care. ${ }^{\prime 11}$ Many titles are given to this type of healthcare provider, depending on which country they work in. Lady Health Workers in Pakistan provide maternal and child health services; técnicos de cirugía provide surgical care in Mozambique; Clinical Officers provide diagnostic and treatment services at the primary care level and in hospitals in East Africa; Health Assistants staff health posts and Auxiliary Health Workers 
sub-health posts in Nepal; and Physician Assistants provide a range of specific services in the United States. ${ }^{42-44}$

While there is an assumption by some that MLWs are a cheap and easy solution to the needs of poorer people in low- and middle-income countries, this is not borne out by international experience. MLWs are a contemporary and international phenomenon. In the US, physician assistants (PAs) complement the work of doctors in carrying out minor surgery, tasks in general practice and emergency care and administering anaesthesia. Indeed, this is a well-established cadre of worker introduced in the 1960s and there are currently over 140 accredited PA training programs in the US, 53 percent of them having been established between 1993 and 2002.45 The US experience has influenced thinking in the United Kingdom, where this cadre has been introduced more recently. ${ }^{46}$ Canada too is considering extending the role of similar providers - active in some Canadian provinces and the Canadian army - into the national health system more generally. ${ }^{47}$ Similarly, in Australia, the introduction of PAs is being piloted. ${ }^{48,49}$ Clinical officers have formed the backbone of primary care in East Africa for some 30-40 years, with over 10,000 trained in Uganda, Tanzania and Kenya. ${ }^{50}$ MLWs are also represented in large numbers in Southeast Asia. ${ }^{42}$

Training more MLWs features prominently in national workforce plans, perhaps nowhere more so than in Africa ${ }^{51-54}$ For instance, Zambia plans to increase numbers from 1000 to 2600; Lesotho to raise the annual graduation rate of nurse officers by 42 percent; and Ghana to double its output of medical assistants in the next 2 years. Ethiopia has produced a 'flooding and retention' strategy, and accelerated training to increase the number of health officers and extension workers to 5000 by $2010 . .^{50}$

Training of MLWs varies. Those that enter this field with pre-existing medical training (mostly nurses), receive top-up training which can be very short, although the length of training for those who will take on generalist roles is about one year. People who enter directly into the category receive training that ranges from 2 to 4 years and in most cases, undertake some kind of supervised clerical placement where they hone their skills; this may be during their training or afterwards in the form of a supervised internship. ${ }^{42}$

For many common conditions, effective, cost-efficient interventions exist that, if more widely implemented, would significantly decrease preventable mortality in Africa and Asia. ${ }^{55,56}$ The attraction of MLWs is that they can improve health service coverage and provide good quality care. In contrast to doctors and nurses, MLWs currently are less able to migrate as they do not hold a transferable qualification. The potential of MLWs to improve access, provide quality care and to remain in areas where they are 
needed, is explored below. We then discuss the potential of this category of worker to impact on population health.

\section{Improved access to care}

For many low resource countries, MLWs are the backbone of the health service. Research into the contribution of mid-level providers indicates that they do indeed improve access to care for underserved populations in both developed and developing countries. ${ }^{57,58}$ MLWs have made trauma care more accessible in the US and increased access to reproductive health services, in particular abortion services, in a number of countries in the developed and developing world. ${ }^{59,60}$ Wide access to HIV treatment in Africa was achieved through the use of MLWs and in some instances, people with even less formal training. ${ }^{61,62}$

\section{Quality of care}

The assertion that providers other than doctors can provide care of equivalent quality has been investigated. A systematic review of nurse-led primary care demonstrated that nurses achieve health outcomes equal to those of general practitioners with good patient satisfaction. ${ }^{63}$ In relation to chronic disease care, a Cochrane review concluded that nurses "can even replace physicians in delivering many aspects of diabetes care if detailed management protocols are available or if they receive training." ${ }^{64}$ Comparing nurse-led with usual (doctor-led) care, outcomes showed improved glycaemic control, lower mortality and fewer complications. ${ }^{65}$ However, a randomised trial indicated that nurse practitioners supplement rather than substitute for doctors with whom they work, while providing a wider range of services ${ }^{66}$

There is less systematic evidence available on the quality of care provided in low resource settings. In a retrospective cohort analysis of patients in a Mozambican HAART program, outcomes were similar for MLWs and doctors. Based on pharmacy records, patients were more likely to have made a quarterly visit if managed by a MLW and to demonstrate optimal adherence six months after starting therapy. Often, the proximity of MLWs to the population served to enhance access to healthcare. Rwanda transferred several tasks from physicians to nurses trained in HIV management, while the physicians took on more supervisory and mentoring roles. Improvement in CD4 count, correct prescriptions, patient monitoring and overall survival were similar between nurses and physicians. ${ }^{67}$

In Malawi, clinical officers conducted 93 percent of major obstetric operations in government hospitals with no significant differences in post- 
operative outcome, well-being, stillbirths or neonatal mortality, when compared with medical officers. Evaluations of the performance of MLWs in Mozambique showed no significant difference in outcome when compared to medical specialists. ${ }^{42}$ In some instances in Malawi, outcomes were equally poor, with the same low proportion of doctors (20 percent) and MLWs (22 percent) using an adequate diagnostic process when examining children under 5 years old ${ }^{68}$ MLWs have also been shown to provide safe and effective abortion and anaesthetic services. ${ }^{69-71}$

There are data to indicate that MLWs are an efficient as well as effective investment. Surgery by MLWs in Mozambique produced the same outcome as doctors whose training cost ten times that of the técnicos de cirugía. MLWs trained to deliver a service with shorter instruction were found to perform those tasks confidently in district services where there is less specialist support. Junior doctors sent to rural hospitals in Mozambique were dependant on senior medical support for longer periods compared to assistant medical officers. ${ }^{72}$ A financial model developed by Chung demonstrated that 942 hours of nurse time freed up 737 hours of physician time, which could then be expended on more complex cases in non-HIV fields, providing increased physician capacity for the health system as a whole. ${ }^{67}$

While more evidence is desirable, there seems to be no reason to discard the idea that, for a number of health conditions, MLWs can provide equivalent quality care to doctors. MLWs with appropriate and adequate training who are provided with continued support and supervision can indeed provide care comparable to medical professionals. ${ }^{42}$ Such training and support, however, is not guaranteed in low resource settings.

\section{Retention and migration}

Issues of retention and migration have not been a feature of research in developed countries. Here we review what is known in low resource settings. One study has confirmed that MLWs are more likely to remain in service in comparison to doctors. Seven years after the graduation of técnicos de cirugía in Mozambique, more than 80 percent were still working at district hospitals, whereas nearly all the medical doctors posted there had left within three years. ${ }^{73}$ Anyone visiting health centres in Africa will meet dedicated clinical officers in remote settings who have been working there for decades. But there is little published data on retention and migration of these staff. There is also data indicating that, while in their health posts, they may spend significant time engaged in other activities to supplement their salaries, including private fee-for-service care. ${ }^{74}$ 
There is an assumption that MLWs require less investment than medical professionals, and will tolerate low salaries and poor living and working conditions. This approach is short-sighted. In the Pacific region, low pay was associated with difficulties in retention, ${ }^{41}$ and poor supervision and lack of training opportunities appeared responsible for attrition of this cadre. ${ }^{42,75}$ If MLWs can provide some answers to the health needs of populations, it seems important to invest adequately in them, but they may have a lesser tendency to emigrate than doctors.

\section{Impact on population health}

There is, however, reason to be cautious about the degree to which MLWs alone may impact on population health in low- and middle-income countries. Addressing the social determinants of health is essential and often ignored or may even be undermined, such as when - in several settings - water supply was privatised and rendered too expensive. ${ }^{24,76}$ Without concomitant investment in programs and processes to address the social determinants of health, it is unrealistic to expect a single category of health worker to make the health impact that is required.

Secondly, in countries with less well functioning health systems, existing staff may work in situations where salaries are so low they do not earn a living wage and thus engage in other activities to meet their basic needs. Moreover, there tends to be frustration with bureaucratic procedures, inflexible planning and shortages of equipment, medications and supplies. ${ }^{13}$ Healthcare personnel may be poorly supervised, unsupported and not acknowledged, and many work where leadership is weak or even absent. ${ }^{77-79}$

Even though this cadre has been in existence in Africa for over 30 years, there is still no recognised career path for MLWs, and their level of expertise and qualification is not routinely linked to pay levels ${ }^{42}$ These factors affect the motivation of health workers, which is linked to the quality of care they provide.$^{80}$ If care is inadequate because of lack of supplies or underperforming staff, it is unlikely that a positive impact on population health will result. Unless these issues are addressed, it is unclear how introducing new, albeit additional, staff into the health system will make the expected contribution. Fascination with the notion of a 'magic bullet' - a quick single intervention to solve all problems - has undermined the development of health systems in poor countries. Where health systems have developed effectively, features have included "sustained investments for many decades in health infrastructure, capacity building of personnel and in improving the organizational and managerial efficiency". ${ }^{81}$ 


\section{NIGERIA: A CASE-STUDY}

Nigeria is the most populous country in sub-Saharan Africa, with a population of almost 150 million people.$^{82}$ It is a multi-ethnic country with Ibo, Yoruba and Hausa being the three major ethnic groups. Nigeria has 36 states with a Federal Capital Territory in Abuja. There are 774 local government areas. The Nigerian health system includes orthodox, alternative and traditional systems of healthcare delivery.

There are three levels of orthodox healthcare delivery: primary, secondary and tertiary. The country has a young population (i.e., 45 percent under 15 years of age) and a disease profile of both developed (non-communicable disease) and developing (communicable disease) countries - the increasingly common 'double burden'. There is no functional national health insurance. Of total health expenditures, government covers 25.5 percent, while private expenditure comprises the remaining 74.5 percent, and 91 percent of private expenditures are out-of-pocket. ${ }^{83}$

In the formal health sector, a PHC approach drives national health policy. Following the Declaration of Alma-Ata, there were serious attempts at health system reform, based on the principles of PHC and resulting in the National Health Policy of 1988. However, the policy failed to create a unified system of care or address finance and staffing for competent local leadership. ${ }^{84}$

The National Health Policy (developed in 1984, adopted in 1988 and revised in 2004) establishes PHC as the framework to improve services for the population. The policy intends that a comprehensive healthcare system, delivered through health centres, be the main thrust for achieving good population health status. In practice, however, priority is given to curative services, with poor funding of preventive healthcare and a lack of strong leadership to drive a PHC approach, with consequent low levels of coverage. This is reflected in indicators such as immunization rates which are below 70 percent for measles, mumps and rubella (MMR). Maternal mortality rates are 1100/10,000 live births, and contraceptive prevalence is 13 percent. ${ }^{85}$ The priority given to curative services fails to address the basic health problems of the country, which require the application of well known and cost-effective public health programmes. ${ }^{86}$

According to National Health Policy, comprehensive care delivered through the primary health centres should include maternal, newborn and child health and family planning. However, these centres are largely understaffed with medications and supplies often out of stock. Improvement in key health indicators has been slow and today Nigeria ranks among countries with the highest child and maternal mortality rates. Major 
contributors to the national disease burden are malaria, tuberculosis (TB) and HIV/AIDS.

Malaria is a major health and developmental problem, with a prevalence of 919 cases per 100,000 population. It is by far the most important cause of morbidity and mortality in infants and young children: about 75 percent of malaria deaths occur in children under 5 and one in ten maternal deaths is due to malaria ${ }^{86}$ The HIV/AIDS epidemic unfolded on a large scale in Nigeria with an estimated adult prevalence of 3.6 percent; nearly 3.0 million people are living with the virus. In 2009 alone, there were about 192,000 AIDS related deaths..$^{87}$ Tuberculosis cases increased dramatically with the onset of HIV/AIDS, with an estimated prevalence of 521 cases per 100,000 population in 2007 . About 27 percent of adults with tuberculosis are also infected with HIV. ${ }^{88}$ Unlike most of sub-Saharan Africa, rural areas in Nigeria have a higher HIV/AIDS prevalence than urban areas. ${ }^{86}$

\section{The health workforce in Nigeria}

Nigeria has high numbers of healthcare providers, who together make up the largest human resource for health in Africa. In 2007, there were 52,408 doctors, 128,918 nurses, and 90,489 midwives registered, which translates into about 35 doctors and 86 nurses per 100,000 population. ${ }^{86}$ This compares with the sub-Saharan average of 15 doctors and 72 nurses per 100,000 population. ${ }^{11}$

A large proportion of the health workforce is in the commercial city of Lagos. Efforts have been made to redistribute the workforce so that it is more equitably spread. About 60 percent of the states in Nigeria provide incentives to health workers that volunteer to serve in rural areas, while others make rural service a condition for certain promotions. There is the National Youth Service Corps (NYSC) that is mandatory for all new university and polytechnic graduates.

Hitherto, nurses and midwives did not participate in the one-year service because their training was not university-based. However, to ensure that nursing and midwifery services are available in all villages and towns, nurses and midwives will now fulfil the mandatory one year national service, a recommendation of the committee established to reduce maternal mortality. ${ }^{84} \mathrm{~A}$ new initiative of the current administration re-engages retired, registered nurse-midwives still fit to work, to provide midwifery services, particularly in rural areas, in a bid to bring down the high maternal mortality rates. 


\section{Health workforce production}

Health workers are produced in designated training institutions. These institutions are poorly distributed in favour of southern parts of the country. Furthermore, nursing and midwifery schools have limited the enrollment of new students to 50 per annum in an effort to ensure that standards are maintained.

Workers are produced at various educational levels including certificate, diploma, graduate and postgraduate. The minimum qualification for formal registration as a health worker is graduate-level training. Another constraint on health worker production is the acute shortage of intern posts for doctors, dentists, pharmacists and laboratory scientists as well as a shortage of residency posts for doctors and dentists..$^{89,90}$

There is no school of public health in Nigeria, although most medical schools have small departments of community health, mainly for undergraduate training. A lack of public health schools focused on postgraduate professional education, leadership and research, results in serious limitations in the professional health workforce. In addition, the lack of bachelors and masters-level public health education, and service management training, results in weak capacity to promote public health programmes and to lead health services and systems.

In sum, the problems of the health workforce in Nigeria include: low salaries, health worker shortages particularly in rural and remote areas, skill-mix imbalances coupled with a curative orientation, maldistribution of specialists, a negative working environment, a weak evidence base, the challenge of HIV/AIDS, out-migration, and inadequate investment in the health sector.

\section{THE WAY FORWARD}

How should the New Public Health address the healthcare needs of populations worldwide? As stated by the WHO Director-General, "Ultimate responsibility for the performance of a country's health system lies with government." ${ }^{91}$ Government remains the leverage point for health workforce development as well. Its role is to: set policy, secure financing for health services, support education, and operate the public health sector while regulating the private sector. The government needs to have national workforce strategic plans to guide enhanced investments in human resources, and to address the mix of professionals at every level. 
New pressures on the health workforce in developing countries have emerged during the last two decades. The workforce has had to address a growing burden of chronic disease, spanning HIV/AIDS and noncommunicable illness, which requires a continuum of care, in particular community-based care. Technological advances (including diagnostics well-suited to home and community use) are now available and this makes care options that include properly integrated community workers more attractive.

It takes decades to build a qualified health workforce. Multidisciplinary health teams - including clinicians, nurses, MLWs and community health workers - together with public health leaders and workers with a populationbased approach to healthcare, are required. It is essential however, to review teaching methods and materials to ensure that they are current and relevant. Urgent attention to training approaches for mid-level and community health workers is needed. Innovative approaches to teaching in industrialised and developing countries must be considered, with state-of-the-art teaching materials and continuing education through the creative use of information and communications technology.

All countries can accelerate health gains by investing in and managing their health workforce more strategically. Diverse national circumstances mean that solutions must be crafted to unique country challenges. Successful strategies should be country-based and country-led, focusing on the frontline in communities, and backed by appropriate international reinforcement.

While addressing migration is important, as illustrated by the $59^{\text {th }}$ World Health Assembly ${ }^{92}$ call to countries to address migration of health personnel from developing countries, retention is only possible if locations of placements within developing countries (for example, in remote and rural areas) are made appealing to the workforce.

Health systems interventions, in particular the management of health workers, have to move away from business-as-usual. The potential 'agency' of individuals at multiple levels in the health system must be recognised and promoted. This cannot be achieved in systems when top-down, "onesize-fits-all" programs are introduced one after another. For public health systems in Africa to improve, the health workforce needs to work in an environment that supports and values them. Interventions that attempt to address this, such as professionalisation and creating organisational spaces to promote self-evaluation and shared learning, have been put forward. A need for posts for mentors - skilled people able to engage with health workers at the site of service delivery - is also suggested. This demands that health workforce plans go beyond a focus on additional numbers and cadres. A cultural shift is required which promotes 'agency' - the 
willingness of individuals in the health system to act on pressing issues and the organisational space to take such action..$^{93}$

Education for managing the health workforce for better performance should bring together the health and educational sectors in strategic partnership to achieve three core objectives: coverage, motivation and competence. Coverage strategies promote numeric adequacy, appropriate skill mixes and outreach to vulnerable populations. Motivation strategies focus on adequate remuneration, a positive work environment, opportunities for career development and supportive health systems. Competencies are advanced through educating for appropriate attitudes and skills, creating conditions for continuous learning, and cultivating leadership, entrepreneurship and innovation. All these efforts should be oriented toward building national capacity. ${ }^{9}$

Workforce development is not merely a technical process - it is also political. It demands a strong action-coalition across all stakeholders with diverse interests. Health workers must be at the centre, but collaboration must reach beyond the health sector to finance, education and other ministries, and beyond government to academic leaders, professional associations, labour unions, educational institutions and non-governmental organisations. All should be involved in setting national goals, designing strategies, drawing up plans, and implementing policies and programs.

Good data and effective operational research and program evaluations, invariably scarce, are needed most. They are essential to inform policy makers and senior managers and to guide much needed efforts to develop an effective health workforce that can assure the health of populations.

These challenges, while daunting, should be addressed with the highest priority. The lofty goal of better public health is a global challenge but one that is addressable with 'healthy' healthcare systems. These must include adequate numbers and an adequate mix of clinical professionals, MLWs and community health workers. Fundamental to achieving this kind of broad system-wide approach in developing countries is a change in practice and attitude of international funding agencies, both public (bi- and multilaterals) and private. There is a consensus on the need to build better health systems. Further short-term, single-disease focused and technology-only interventions will not make possible the kind of changes required. More of the same will result in the same health systems challenges that we see today. A longer term view is required, with the aim of achieving slow, incremental change - it is the long-term sustainable "bang for the buck" that should be valued over the short term but bigger "bang". Cost-effectiveness assessments need to include a measure that reflects long-term sustainability. 
The solution to health workforce issues in low resource settings is complex and various approaches in combination are needed. Some require structural and managerial changes in health systems and human resource practice. Others concern improvement in salaries and living and working conditions for healthcare providers. In this article we looked specifically at two categories of healthcare worker - community-based health workers and mid-level workers - and assessed their potential to contribute to solutions.

\section{Acknowledgements}

The authors are grateful to Annette Gerritsen for searching the literature on community health worker experience, Dawn Dalby for editorial assistance, and Kathy Kahn and Joan Bickford for assistance with references. Sharon Fonn was a policy scholar at the Woodrow Wilson Center for International Scholars at the time of writing this article.

Conflicts of interest: None declared.

\section{REFERENCES}

1. Dussault G, Franceschini MC. Not enough there, too many here: understanding geographical imbalances in the distribution of the health workforce. Hum Resour Health. 2006;4:12.

2. Speybroeck N, Kinfu Y, Dal Poz MR, Evans DB. Reassessing the relationship between human resources for health, intervention coverage and health outcomes. Evidence and Information For Policy. Geneva: World Health Organization ; 2006. Available from URL: https://www.who.int/hrh/documents/reassessing relationship.pdf (Accessed 13 May, 2010).

3. Kinfu Y, Dal Poz MR, Mercer H, Evans DB. The health worker shortage in Africa: are enough physicians and nurses being trained? Bull World Health Organ. 2009;87(3)225-39.

4. Parfitt B. Health reform: the human resource challenges for Central Asian Commonwealth of Independent States (CIS) countries. Collegian. 2009;16(1): 36-40.

5. Dolea C, Stormont L, Braicheta JM. Evaluated strategies to increase attraction and retention of health workers in remote and rural areas. Bull World Health Organ. 2010;88:379-85.

6. Chen LC. Striking the right balance: health workforce retention in remote and rural areas. Bull World Health Organ. 2010;88:323.

7. Sim F, Lock K, McKee M. Maximizing the contribution of the public health workforce: the English experience. Bull World Health Organ. 2007;85:935-8. Available from URL: http://www.who.int/bulletin/volumes/85/12/07-044289. pdf (Accessed 13 May, 2010).

8. World Health Organization. Working together for health: the world health report 2006, Geneva: World Health Organization; 2006. Available from URL: http:// www.who.int/whr/2006/whr06_en.pdf (Accessed 17 May, 2010). 
9. Joint Learning Initiative. Human resources for health; overcoming the crisis. Washington (DC): The President and Fellows of Harvard College; 2004. Available from URL: http://www.who.int/hrh/documents/JLi_hrh_report.pdf (Accessed 13 May, 2010).

10. Beaglehole R, Sanders D, Dal Poz M. The public health workforce in subSaharan Africa: challenges and opportunities. Ethn Dis. 2003; 13 (2 Suppl 2): S24-30.

11. World Health Organization, Regional Office for Africa. The African regional health report, 2006: the health of the people. Available from URL: http:// whqlibdoc.who.int/afro/2006/9290231033_rev_eng.pdf or http://www.who.int/ bulletin/africanhealth/en/index.html (Accessed 13 May, 2010).

12. UNAIDS. 2008 report on the global Aids epidemic. Geneva: UNAIDS; 2008. http://whqlibdoc.who.int/unaids/2008/9789291737178_eng.pdf (Accessed 13 May, 2010).

13. Hongoro C, McPake B. How to bridge the gap in human resources for health. Lancet. 2004;364:1451-6.

14. Abdool Karim SS, Churchyard GJ, Abdool Karim Q, Lawn SD. HIV infection and tuberculosis in South Africa: an urgent need to escalate the public health response. Lancet. 2009;374:921-33.

15. Adjuik M, Smith T, Clark S, Todd J, Garrib A, Kinfu Y, et al. Cause-specific mortality in sub-Saharan Africa and Bangladesh, Bull World Health Organ. 2006;84:181-92.

16. Tollman SM, Kahn K, Sartorius B, Collinson MA, Clark SJ, Garenne ML. Implications of mortality transition for primary health care in rural South Africa: a population-based surveillance study. Lancet. 2008;372:893-901.

17. World Health Organization. World health report 2000: Health systems; improving performance. Geneva: World Health Organization; 2000. Available from URL: http://www.who.int/whr/2000/en/whr00_en.pdf (Accessed 13 May, 2010),

18. Frenk J. Bridging the divide: global lessons learned from evidence-based health policy in Mexico. Lancet. 2006;368:954-61.

19. Chopra M, Lawn JE, Sanders D, Barron P, Abdool Karim SS, Bradshaw D, et al. Achieving the health Millennium Development Goals for South Africa: challenges and priorities. Lancet. 2009; 374:1023-31.

20. Goudge J, Gilson L, Russell S, Gumede T, Mills A. The household costs of health care in rural South Africa with free primary public care and hospital exemptions for the poor. Trop Med Int Health. 2009;14:458-67.

21. Chan M. Return to Alma-Ata. Lancet. 2008;372:865-6.

22. World Health Organization. The world health report 2008; primary health care now more than ever. Geneva: World Health Organization; 2008. Available from URL: http://www.who.int/whr/2008/whr08_en.pdf (Accessed 13 May, 2010).

23. Spinaci S, Currat L, Shetty P, Crowell V, Kehler J. Tough choices: investing in health for development: experiences from national follow-up to the Commission on Macroeconomics and Health. Geneva: World Health Organization; 2006. 
Available from URL: http://www.who.int/macrohealth/documents/report_ and_cover.pdf (Accessed 13 May, 2010).

24. Commission on Social Determinants of Health. Closing the gap in a generation: health equity through action on the social determinants of health. Final Report of the Commission on Social Determinants of Health Geneva: World Health Organization; 2008. Available from URL: http://whqlibdoc.who.int/ publications/2008/9789241563703_eng.pdf (Accessed 13 May, 2010).

25. Tollman S, Doherty J, Mulligan JA. General primary care. (Ch. 64) In: Jamison DT, Breman JG, Measham AR, Alleyne G, Claeson M, Evans DB, et al. editors. Disease control priorities and developing countries. $2^{\text {nd }}$ ed. Washington (DC) and New York: World Bank and Oxford University Press; 2006. p.1193210.

26. Laxminarayan R, Mills AJ, Brennan JG, Measham AR, Alleyne G, Claeson M, et al. Advancement of global health: key messages from the Disease Control Priorities Project. Lancet. 2006;367:1193-208.

27. Frenk J. Reinventing primary health care: the need for systems integration. Lancet. 3009;374:170-3.

28. Haji M, Durairaj V, Zurn P, Stormont L, Mapunda M. Emerging opportunities for recruiting and retaining a rural health workforce through decentralized health financing systems. Bull World Health Organ 2010;88:397-9.

29. Gilks CF, Crowley S, Ekpini R, Gove S, Perriens J, Souteyrand Y, et al. The WHO public-health approach to antiretroviral treatment against HIV in resource-limited settings. Lancet. 2006;368:505-10.

30. Haines A, Sanders D, Lehmann U, Rowe AK, Lawn JE, Jan S, et al. Achieving child survival goals: potential contribution of community health workers. Lancet. 2007;369:2121-31.

31. Gilson L, Walt G, Heggenhougen K, Owuor-Omondi L, Perera M, Ross D, et al. National community health worker programs: how can they be strengthened? J Public Health Policy. 1989;10:518-32.

32. Hermann K, Van Damme W, Pariyo GW, Schouten E, Assefa Y, Cirera A, et al. Community health workers for ART in sub-Saharan Africa: learning from experience - capitalizing on new opportunities. Hum Resour Health. 2009; $7: 31$.

33. Schneider H, Hlophe H, van Rensberg D. Community health workers and the response to HIV/AIDS in South Africa: tensions and prospects. Health Policy Plan. 2008;23:179-87.

34. Samb B, Celletti F. Holloway J, Van Damme W, De Cock KM, Dybul M. Rapid expansion of the health workforce in response to the HIV epidemic. N Engl J Med. 2007;357:2510-4.

35. Chang LW, Alamo S, Guma S, Christopher J, Suntoke T, Omasete R, et al. Twoyear virologic outcomes of an alternative AIDS care model: evaluation of a peer health worker and nurse-staffed community-based program in Uganda. J Acquir Immune Defic Syndr. 2009;50:276-82. 
36. Wouters E, Van Damme W, Van Loon F, van Rensburg D, Meulemans H. Public-sector ART in Free State Province, South Africa: community support as an important determinant of outcome. Soc Sci Med. 2009;69:1177-85.

37. Harvey SA, Jennings L, Chinyama M, Masaninga F, Mulholland K, Bell DR. Improving community health worker use of malaria rapid diagnostic tests in Zambia: package instruction, job aid and job aid-plus-training. Malar J. 2008; 7:160.

38. Lewin SA, Dick J, Pond P, Zwarenstein M, Aja G, van Wyk B, et al. Lay health workers in primary and community health care. Cochrane Database Syst Rev. 2005;(1):CD004015.

39. Webster PC. Uganda registers successes with child-health volunteers. Lancet. 2009;374:1735-6.

40. Clarke M, Dick J, Zwarenstein M, Lombard CJ, Diwan VK. Lay health worker intervention with choice of DOT superior to standard TB care for farm dwellers in South Africa: a cluster randomized control trial. Int J Tuberc Lung Dis. 2005:673-9.

41. World Health Organization, Western Pacific Region. Mid-level and nurse practitioners in the Pacific: models and issues. Manila: World Health Organization, Western Pacific Region; 2001. Available from URL: http:// www.wpro.who.int/internet/resources.ashx/NUR/nursescoverall.pdf(Accessed 14 May, 2010).

42. Lehmann U. Mid-level workers. The state of the evidence on programmes, activities, costs and impact on health outcomes. A literature review. Geneva: World Health Organization; 2008. Available from URL: http://www.who.int/ hrh/MLHW_review_2008.pdf (Accessed 14 May, 2010).

43. McAuliffe E, Bowie C, Manafa O, Maseko F, MacLachlan M, Hevey D, et al. Measuring and managing the work environment of the mid-level provider the neglected human resource. Hum Resour Health. 2009;7:13.

44. McPake B, Mensah K. Task shifting in health care in resource-poor countries. Lancet. 2008;372:870-1.

45. Glicken AD. Excellence in physician assistant training through faculty development. Acad Med. 2008;83:1107-10.

46. Stewart AC, Catanzaro R. Can physician assistants be effective in the UK? Clin Med. 2005;5: 344-8.

47. Ashton CW, Aiken A, Duffie D. Physician assistants - a solution to wait times in Canada? Healthc Manage Forum. 2007;20:38-42.

48. Kamalakanthan A, Jackson S. Doctor supply in Australia: rural-urban imbalances and regulated supply. Aust J Prim Health. 2009;15:3-8.

49. Sweet M. Australia to try US-style physician assistants to increase health workforce. BMJ. 2008;337:a1407.

50. Mullan F, Frehywot S. Non-physician clinicians in 47 sub-Saharan African countries. Lancet. 2007;370:2158-63.

51. Kurowski C, Wyss K. Abdulla S, Yémadji N’D, Mills A. 2004 Human resources for health: requirements and availability in the context of scaling-up priority interventions in low-income countries. Case studies from Tanzania and Chad. 
HEFP working paper 01/04. London: LSHTM;2004. Available from URL: http://www.hefp.lshtm.ac.uk/publications/downloads/working_papers/01_04. pdf (Accessed 12 May, 2010)

52. Wools-Kaloustian K, Kimalyo S. Extending HIV care in resource-limited settings. Current HIV/AIDS reports. 2006;3:182-6.

53. Record R, Mohiddin A. An economic perspective on Malawi's medical "brain drain". Globalization Health. 2006;2:12.

54. Adano U. The health worker recruitment and deployment process in Kenya: an emergency hiring program. Hum Resour Health. 2008;6:19.

55. Nanda G, Switlick K, Lule E. Accelerating progress towards achieving the MDG to improve maternal deaths. A collection of promising approaches. Health, Nutrition and Population (HNP) discussions paper. Washington (DC); World Bank; 2005. Available from URL: http://siteresources.worldbank. org/HEALTHNUTRITIONANDPOPULATION/Resources/2816271095698140167/NandaAcceleratingProgresswithCover.pdf (Accessed 14 May, 2010).

56. Jones G, Steketee RW, Black RE, Bhutta ZA, Morris S. How many child deaths can we prevent this year? Lancet. 2003;362:65-71.

57. Staton FS, Bhosle MJ, Camacho FT, Feldman SR, Balkrisnan R. How PAs improve access to care for the underserved. JAAPA. 2007;20:32,34,36 passim.

58. Keni BH. Training competent and effective primary health care workers to fill a void in the outer islands health service delivery of the Marshall Islands of Micronesia. Hum Resour Health. 2006;4:27.

59. Mikhail J, Millerz W, Wagner J. Midlevel practitioner role evolution in an American College of Surgeons - verified trauma surgery service: the 23-year experience at Hurley Medical Center. J Trauma Nurs. 2009;16:33-40.

60. Berer M. Provision of abortion by mid-level providers: international policy, practice and perspectives. Bull World Health Organ. 2009;87:58-63.

61. Médicins Sans Frontières. Help wanted. Confronting the health care worker crisis to expand access to HIV/AIDS treatment. Johannesburg: Médicins Sans Frontières; 2007. Available from URL: http://www.msf.org/source/ countries/ africa/southafrica/2007/Help_wanted.pdf (Accessed 14 May, 2010).

62. Médicins Sans Frontières. Decentralising free nurse-based HIV/TB care and treatment at the primary health care level in rural Lesotho: 2007 mid-year progress report. Available from URL: http://msf.org.za/Docs/2007_Mid-Year_ Progress_Report-FINAL.pdf (Accessed 14 May, 2010).

63. Horrocks S, Anderson E, Salisbury C. Systematic review of whether nurse practitioners working in primary care can provide equivalent care to doctors. BMJ. 2002;324:819-23.

64. Renders CM, Valk GD, Griffin SJ, Wagner E, van Eijk JThM, Assendelft WJJ. Interventions to improve the management of diabetes mellitus in primary care, outpatient and community settings. Cochrane Database of Systematic Reviews. 2000; Issue 4. Art. No: CD001481.

65. Bodenheimer T, MacGregor K, Stothart N. Nurses as leaders in chronic care. BMJ. 2005;330:612-3. 
66. Laurant MGH, Hermens RPMG, Braspenning JCC, Sibbald B, Grol RPTM. Impact of nurse practitioners on workload of general practitioners: a randomised controlled trial. BMJ. 2004;328:927-30.

67. AIDSMap. Task shifting: successes from Mozambique and Rwanda 05/09/08. Available from URL: http://www.aidsmap.co.uk/cms1277951.asp (Accessed 20 May, 2010)

68. Dovlo D. Using mid-level cadres as substitutes for internationally mobile health professionals in Africa. A desk review. Hum Resour Health. 2004;2:7.

69. Yarnall J, Swica Y, Winikoff B. Non-physician clinicians can safely provide first trimester medical abortion. Reproductive Health Matters. 2009:17:61-69.

70. Weller JM, Merry AF, Robinson BJ, Warman GR, Janssen A. The impact of trained assistance on error rates in anaesthesia: a stimulation-based randomised controlled trial. Anaesthesia, 2009;64:126-30.

71. Roy CL, Liang CL, Lund M, Boyd C, Katz JT, McKean S, et al. Implementation of a physician assistant/hospitalist service in an academic medical center: impact on efficiency and patient outcomes. J Hosp Med. 2008;3:361-8.

72. Pereira C, Cumbi A, Malalane R, Vaz F, McCord C, Bacci A, Bergstrom S. Meeting the need for emergency obstetric care in Mozambique: work performance and histories of medical doctors and assistant medical officers trained for surgery. BJOG. 2007;114:1530-3.

73. Cumbi A, Pereira C, Malalane R, Vaz F, McCord C, Bacci A, Bergstrom S. Major surgery delegation to mid-level health practitioners in Mozambique: health professionals' perceptions. Hum Resour Health. 2007;5:27

74. McCoy D, Bennett S, Witter S, Pond B, Baker B, Gow J, et al. Salaries and incomes of health workers in sub-Saharan Africa. Lancet. 2008;371:675-81.

75. Henderson LN, Tulloch J. Incentives for retaining and motivating health workers in Pacific and Asian countries. Hum Resour Health. 2008;6:18.

76. Udin S. The no-nonsense guide to world health. Oxford; New Internationalist; 2007.

77. Willis-Shattuck M, Bidwell P, Thomas S, Wyness L, Blaauw D, Ditlopo P. Motivation and retention of health workers in developing countries: a systematic review. BMC Health Services Research. 2008;8:247.

78. Penn-Kekana L, Blaauw D, Tint KS, Monareng D, Chege J. Nursing staff dynamics and implications for maternal health provision in public health facilities in the context of HIV/AIDS. Johannesburg (SA): Centre for Health Policy, University of Witwatersrand Frontiers in Reproductive Health Population Council; 2005. Available from URL: http://web.wits.ac.za/NR/ rdonlyres/AEB72B9A-AD32-47B3-A19F-C976A1303960/0/FR109_SA_ Nursing_Staff.pdf (Accessed 14 May, 2010).

79. Chandler CI, Chonya S, Mtei F, Reyburn H, Whitty CJ. Motivation, money and respect: a mixed-method study of Tanzanian non-physician clinicians. Soc Sci Med. 2009;68:2078-88.

80. Rowe AK, de Savigny D, Lanata CF, Victora CG. How we achieve and maintain high-quality performance of health workers in low-resource settings. Lancet. 2005;366:1026-35. 
81. Health system reform initiatives in Tamil Nadu: Contribution to improvements in sexual and reproductive health services. Available from URL: http://web. wits.ac.za/Academic/health/PublicHealth/ (Accessed 14 May, 2010).

82. World Health Organization. WHO African Region. Nigeria: health profile. 2006. Available from URL: http://www.who.int/countries/nga/nga/en/ and http://www.who.int/gho/countries/nga.pdf (Accessed 14 May, 2010).

83. World Health Organization. Country health system fact sheet, 2006. Nigeria. Available from URL: http://www.afro.who.int/index.php?option=com_conte nt\&view=article \&id=1047\&Itemid=1936 or http://www.afro.who.int/en/ nigeria/who-country-office-nigeria.html (Accessed 14 May, 2010).

84. Tulchinsky TH, Varavikova EA. The new public health: second edition. San Diego: Elsevier Academic Press; 2008. Chapter 15.

85. United Nations International Children's Fund. The state of the world's children, 2009. New York: United Nations; 2009. Available from URL: http://www. unicef.org/publications/files/SOWC_2009_Main__Report_03112009.pdf (Accessed 14 May, 2010).

86. Labiran A. Mafe M. Onajole A. Lambo E. Health workforce country profile for Nigeria: first edition. Nigeria Africa Health Workforce Observatory; 2008 Available from URL: http://www.hrh-observatory.afro.who.int/images/ Document_Centre/nigeria_country_profile.pdf (Accessed 14 May, 2010)

87. National Agency for the Control of AIDS (NACA). United Nations: UNGASS country progress report- reporting period January 2008- December 2009 (March 2010). Available from URL: http://data.unaids.org/pub/Report/2010/ nigeria_2010_country_progress_report_en.pdf (Accessed 3 June, 2010).

88. World Health Organization. Stop TB strategy: Nigeria. Available from URL: http://www.stoptb.org/assets/documents/countries/GlobalReport2009/nga. pdf (Accessed 5 June, 2010).

89. Rourke J. How can medical schools contribute to the education, recruitment and retention of rural physicians in their region. Bull World Health Organ. 2010; 88:395-6.

90. Frehywot S, Mullan F, Payne PW, Ross H. Compulsory service programmes for recruiting health workers in remote and rural areas: do they work? Bull World Health Organ. 2010;88:364-70.

91. World Health Organization. World health report 2000: Health systems improving performance. Geneva: World Health Organization; 2000. Available from URL: http://www.who.int/whr/2000/en/ (Accessed 14 May, 2010).

92. World Health Organization. World Health Assembly 2006. Available from URL: http://www.who.int/mediacentre/events/2006/wha59/en/ (Accessed 14 May, 2010).

93. Fonn S, Ray S, Blaauw D. Innovation to improve health care provision and health systems in sub-Saharan Africa - promoting agency in mid-level workers and district managers. Global Public Health; 2010 (in press). 